IOS Press

\title{
A broader consideration of human factor to enhance sustainable building design
}

\author{
Erminia Attaianese ${ }^{\mathrm{a}}$ \\ Deparment DICATA/LEAS, University of Naples Federico II, Via Tarsia 31, 80135, Naples, Italy
}

\begin{abstract}
The link between ergonomic/human factor and sustainability seems to be clearly evidenced mainly in relation to social dimension of sustainability, in order to contribute to assure corporate social responsibility and global value creation. But the will to establish an equilibrated connection among used resources in human activities, supported by the sustainability perspective, evidences that the contribution of ergonomics/human factors can be effectively enlarged to other aspects, especially in relation to building design. In fact a sustainable building is meant to be a building that contributes, through its characteristics and attribute, to a sustainable development by assuring, in the same time, a decrease of resources use and environmental impact and an increase of health, safety and comfort of the occupants. The purpose of this paper is to analyze in a broader sense the contribution of ergonomic/human factor to design of sustainable building, focusing how ergonomics principles, methodology and techniques can improve building design, enhancing its sustainability performance during all phases of building lifecycle.
\end{abstract}

Keywords: Ergonomics, sustainability, users, management, performances.

\section{Introduction}

The concept of sustainability provides a values set having a cross role among the single sciences and disciplines, bringing a substantial and paradigmatic change in scientific approach, thanks to the integration of fields of knowledge traditionally distant, all contributing to support the will to establish an equilibrated connection among used resources in human activities.

This perspective highlights the necessity to understand needs of all various peoples involved in a process, in their specific context, in order to configure operational scenarios which are sustainable thanks to their ability to meet their expectancies, and, finally, to their capacity to be easily accepted and promoted [1].

Although the explicit reference to the concept of sustainable development is relatively new for ergonomics/human factors domain, the underlying ideas and approaches are not [2]. In fact social dimension of sustainability is clearly connected to human factors, especially to improve sustainable development in global value creation [3].

Contribution of ergonomics/human factors to a sustainable development can be effectively enlarged to other aspects [4], especially in relation to building requirements design, although not much researches focus this issue directly.

\section{Ergonomics/human factors approach for building design}

As it is well known, ergonomics (or human factors) focuses on the understanding of the interactions among humans and other elements of a system, providing theoretical principles, data and methods to design in order to optimise human well-being and overall system performance. The level of optimisation depends on the possibility to understand and explain those system qualities that are able to make the system fit its users' needs. Since ergonomic design of environments bring the same concerns as any other kind of systems, some principles driven by human factors/ergonomics discipline could be taken usefully into account for an ergonomic approach to architectural design. End-users involvement is one of the key aspects of ergonomics. In building design context, active and passive participation of users has increased over the time, especially with the growing interest in quality control, where the role of users' satisfaction has became essential also within the construction sector [5]. In ergonomic method, human variability is an important design principle, since the 
consideration of diversities of people involved in a broad context of situations, with a wide range of capabilities and limitations, brings to focus on the actual activities of the individuals. This approach appears crucial when referred to building users, also considering that people's abilities vary over the time, and the design of built environment has to comply with a lot of age, health and body related changing conditions, concerning physical and mental characteristics.

The respect of human variability leads to overcoming the whole of stereotyped behaviours and standards reference that usually represent the design starting points. It highlights, on the contrary, in ergonomic design of buildings, the consideration of total environment's effects on real people who have to use it.

Moreover ergonomics approach to design reflects a systems oriented method applying to all aspects of human activity. When the system is the built environment, the systemic approach requires that designers move from an attention exclusively reserved for building functions towards the set of actions that users actually perform and that building has to support. In this view each architectural detail can be designed to optimise the execution of activities, providing the best level of users' comfort and satisfaction [6].

\section{From green to sustainable to high performance building}

As the Brundtland Commission has defined, "sustainable development is development that meets the needs of the present without compromising the ability of future generations to meet their own needs", therefore, it is a process where resources exploitation, investment strategies, technology development trends and institution innovations are all harmonized, increasing present and future potentialities for human needs and wishes fulfillment.

More specifically in 1997 the definition adopted by the United Nation in its Agenda for Development, implied that sustainability policy of an organization involves three performances to achieve: economic success, through the wise use of financial resources; social responsibility, assuring the respect for people; environmental responsibility, applying respect for life and the wise management and use of natural resources [7].

When sustainability refers to buildings and construction sector it is mostly referred to the environmental responsibility issues. In fact it has been de- fined as the practice to activate a process that is environmentally responsible and resource-efficient, throughout all building's life-cycle: from locating to design, construction, operation, maintenance, renovation, and demolition. [8]

Even if this practice expands and complements the classical building design concerns of economy, utility, durability and comfort, the current focus that is generally given to natural resources protection is prevalent in design for sustainability buildings. In fact in scientific and technical literature sustainable dimension of construction process is usually defined in two ways, frequently overlapped, but mostly intended as building "greenery", in a restricted sense. Green buildings may be seen as synonymous of environmental friendly, which design is aimed to reduce the overall impact of the built environment on human health and the natural environment.

But by an enlarged view point it has been assumed that a sustainable building has to contribute to a sustainable development, through its characteristics and attributes, safeguarding and maximizing functionality and serviceability as well as aesthetic quality; minimizing life cycle and protecting and/or increasing capital; reducing land use, raw materials and resource depletion, but also reducing malicious impacts on the environment; protecting health, comfort and safety of workers, occupant, users, visitors and neighbors; and preserving cultural values and heritage [9].

In fact while green building is often used interchangeably with sustainable building and related terms, the latter may be better thought of as a form of green building, but with a more stringent goal of buildings that will indefinitely maintain environmental footprints that are small enough that they will not impede future human activity and the functioning of ecosystems [10].

Finally another term recently used for a green or sustainable building is high performance one, a building that integrates and optimizes on a life cycle basis all major high performance attributes, including energy conservation, environment, safety, security, durability, accessibility, cost-benefit, productivity, sustainability, functionality, and operational considerations [10].

\section{Some issues about ergonomics/human factors approach for sustainable performance of buildings}

As people are themselves part of the environment, green and sustainable buildings both include human 
perspective in their design concerns, mainly considering health and well-being of people involved in the design process, particularly in terms of comfort and productivity of occupants [11].

But despite in several studies the inhabitant comfort is included in an environment-friendly building design and a lot of standard tools for sustainable performance rating of buildings and projects have included ergonomic related indicators [12], it can be noticed that human factors indicators are restricted to the ergonomic features of machines, equipments and furniture, considering them as tools able to reduce discomfort and musculoskeletal disorders of occupants. Rarely ergonomics/human factors issue is included in sustainability requirements for architectural detailing of the whole building system, and moreover, for improving building design process [13].

In fact being ergonomic approach aimed to optimise human interactions with systems, in order to make activities more efficient, safe, comfortable and satisfying, architectural design and building construction and management can be enhanced by the consideration of human factors perspective, because it gives the cultural and practical references to envisage how technical solutions and details constituting the building, can be effective, efficient and satisfying as fitting, primary, the whole of needs derived from people's life and work activities they perform, "in or for" it [5].

On the other hand to be sustainable a building has to offer an high performance, not only in environmental terms, as energy efficient but also as all lifecycle durable and effective, and occupant safe, secure and productive. All these aspects can be addressed by human factors approach.

\subsection{Human factors for energy efficiency}

A reduced energy footprint is probably the most widely cited element of sustainable building, since energy use is widely considered a crucial element of the economic costs and environmental impacts. It is generally known that a critical role in the built environment energy consumption is played by buildings end-users, considering that occupants and their behavior influence approximately half of the energy used in buildings. Occupants behavior are affected by more factors: politics and rules imposed by public administrators and legislators; culture, local habits, social conditioning and lifestyles; capability to control building systems, determining reactions of adaptation or rejection of the available technologies. In fact energy consumption in buildings is linked to a general problem of adequacy, involving specificities of both systems and technologies, which are asked to become more and more effective and functional, as well as more conscious procedures for their use. Against the pressing necessity of lifestyles and approaches compatible with the optimal resources consumption, the issue of pervasiveness of appropriate individual and collective behaviors is now emerging. This perspective enhance the role of energy end-users, which are asked to fit their needs to the conscious usage of resources, also by mean of tools and devices controlling more and more sophisticated functions [14] [15].

In this framework ergonomic/human factors it can be particularly helpful for the availability of methodological and operational tools able to analyze human activities, observe and understand needs and expectancies coming from users in order to produce interfaces compatible with them. It is matter of understanding and assessing ways of human-system interaction, as well as designing devices and procedures able to improve their efficiency assuring all stakeholders satisfaction in a balanced relation with environment. In fact it has been considered that if green buildings are designed paying poor attention to users' preferences and needs, they can result in a sort of fragility with respect to their assumed energy performances [16]. Moreover ergonomic approach to the building design process facilitates the selection of the most appropriate technologies; these are supposed to bring an optimized building functioning and, consequently, a waste reduction, thanks to the optimization of built estate management [17].

\subsection{Human factors for functionality and serviceability}

Building functionality and serviceability are both referred to the conditions under which a building is considered useful to their occupants: the first involves building capacity to address hosted activities requirements since the early moment of its fruition by occupants; the latter concerns the conditions beyond which specified service requirements resulting from the planned use are still met. As measure of building utility they are important element of sustainability [10], that imply to protecting and /or increasing the building capital value. In fact it has been stated that the value of a product is defined by the individual needs of the customer, so that it is important to develop a design value that is adequate to specific groups of customers [18]. This also because a product 
is meant to be able to provide use value according to its efficacy [19], considering how it fulfils users needs and increases their satisfaction.

About this issue the human factors approach can implement this issue in building design, by supporting the analysis of the use context, by users needs and expectations gathering and survey and by the observation and description of how all users can/could achieve their goals using the building [5] [20].

\subsection{Human factors for improving operation and maintenance}

Many studies state that maintenance is necessary to achieve efficient building energy performance [21]. Since main scope of maintenance is the continuity in keeping of building and infrastructures estate capacity to perform required functions, it assumes a crucial role for building sustainable management considering the chance it gives for a conscious resources utilization, as every action on a building component has the potential to improve or decrease its efficiency.

Human factors approach can contribute to increase building effectiveness, first of all, by enhancing maintainability. In fact maintenance efficacy is a function of processes efficacy activated by maintenance, and human factors perspective could be crucial in requirements design for planning and executing maintenance activities, directly and indirectly improving environmental performances in their whole. A particular attention has to be reserved to people interactions with technical and social systems, given that clear and effective connections bring to increase autonomous and conscious usage of resources, by effective usage of built environment systems, being this issue widely considered as strategic to encourage environment friendly, an then sustainable, behaviors. From design stage, when performance and physical characteristic of building and durability are influenced by architectural detailing, concerning for example, the impact of design on structures and materials installed as well as the life cycle of each component of building. At the construction and management stage, when unsatisfactory detailing, incorrect selection of building materials, components and systems, lack of standardization have been detected as factors for the occurrence of construction main defects, also caused by incorrect assembly on site or in factory [22], or when built environment spaces and layout create operative space often inaccessible for maintenance tasks; or when facility management of built environment can show ineffective- ness and inefficiency due to lacks in information availability and exchange from different skills involved. At the stage of end-users fruition, when incomprehensible and/or not-easy to control devices of built environment systems, influence resources depletion; and/or when lacks in communication between tenant and maintenance staff can affect effectiveness of building functions due to inadequate programming of maintenance executive process [13].

\subsection{Human factors for protecting occupants comfort}

In a recent literature review it has been deduced that new approaches to indoor comfort are now emerging, all focusing occupants rule. Occupants are becoming more active in shaping indoor conditions through improved means for personal control, by a perspective that assumes the comfort as experienced not only in physiological terms, but also in the psychological, behavioral and social senses. These evidences remark that indoor comfort conditions should be considered as variable and diverse rather than uniform and static, in order to address in the same time users needs and energy efficiency [23]. Adaptive dimension of thermal comfort is not new [24] such as the consideration of human factors in relation to office occupants [25], but less has been applied on psychosocial related aspects [26]. Ergonomic/human factor approach can contribute to focus on buildings inhabitants promoting the consideration of users actual behavior in a very early stage of energy design of building, for a more comprehensive analysis of needs, demands and wishes, and a better articulation of energy/environmental performance targets of built environment. In this framework, individuals behaviors especially at home can be assumed as crucial starting data to collect in sustainable design of building, in order to identify, from those actual behaviors and elements -features and componentsenergy design of building can be improved.

\section{Discussion}

The purpose of this paper was the analysis in a broader sense of the role of ergonomic/human factor in sustainable design of buildings. To reach this purpose, an overview of the state of the art concerning researches and applications is reported and discussed. A detailed identification of ergonomic principles, methodology and techniques more suitable to en- 
hance building sustainability performance within its whole lifecycle has been then provided.

Discussed issues clarify the emerging need of trainee professional skills able to integrate users characteristics and needs into the building requirements definition process. Furthermore, the systemoriented approach brought by ergonomics supports the successful assessment of building sustainability, considering building performances under an wider and integrated perspective.

\section{References}

[1] E. Attaianese, Ergonomics in maintenance for energy sustainable management, in Proceedings of Maintenance and Facility Management Conference, Rome 2224 April, CNIM, Roma, 2009 pp. 15-18

[2] IEA Technical Committee, Human Factors and Sustainable Development, retrieved November 122010 http://www.iea.cc/browse.php?contID=hf_and_sustaina ble dev

[3] K Fischer, C. Hobelsberger, and J. K. Zink, Human factors and sustainable development in global value creation in Challenges and Opportunities Proceedings - 17th Congress of the International Ergonomics Association, August 9 - 14, 2009 Beijing, China, pp. 1-8.

[4] K. Zink, Stakeholder-oriented Management Concepts as Challenge for Macro-Ergonomics - How can macroergonomics successfully contribute to quality and sustainability? , in J. Lindfors, M. Savolainen and S. Väyrynen (Eds) Wellbeing and innovation through ergonomics. Proceedings of NES 18-21 September 2011, Ouli Finland, pp 9-16.

[5] L. Volker and M. Prins, Exploring the possibilities of correlating management with value in architectural design. In: S. Emmitt and M. Prins (Eds.), Proceedings of the CIB W096 Architectural Management. CIB Rotterdam, 2005, pp. 47-59.

[6] E. Attaianese and G. Duca, Human factors and ergonomic principles in building design for life and work activities: an applied, methodology. Theoretical Issues in Ergonomics Science. iFirst 30 September 2010 (2010)

[7] W.R. Blackburn, The sustainable handbook, Earthscan, London, 2007, p. 24

[8] U.S. Environmental Protection Agency. Green Building Basic Information (2009). Retrieved on line December 10, 2009, from http://www.epa.gov/greenbuilding/pubs/about.htm

[9] T. Lutzkendorf, and D. Lorenz, Integrating sustainability into property risk for market transformation, Building Research \& Information, 35:6, (2007) pp. 644-661

[10] E.A. Fischer, Issues in Green Building and the Federal Response: An introduction, Congressional Research Service,7-5700, R40147, Washington D.C., 2010 Retrieved on line August 282011 www.crs.gov

[11] N. G. Miller, D. Pogue, Q. D. Gough and S. M. Davis, Green Buildings and Productivity, Journal of Sustainable Real Estate, 1:1 (2009), pp. 65-89.

[12] A. Hedge, The Sprouting of "Green" Ergonomics. HFES Bulletin 51:12 (2008) pp. 1-3.
[13] E. Attaianese, Human factors in maintenance for a sustainable management of built environment, in J. Lindfors J., M. Savolainen M. and S. Väyrynen (Eds.) Wellbeing and innovation through ergonomics. Proceedings of NES 2011 Oulu, September 18-21 2011, pp $129-134$

[14] S. Flemming, A. Hilliardand and G.A. Jamieson, The need of human factors in the sustainability domain, in Proceedings of the Human Factors and Ergonomics Society 52nd Annual Meeting, 2008, pp. 748-752.

[15] K. B. Janda, Buildings Don't Use Energy: People Do, Architectural Science Review 54 (2011), pp. 15-22.

[16] A. Leaman and B. Bordass, Are users more tolerant of 'green' buildings? Building Research and Information. 35:6, (2007), pp. 662-673.

[17] J. Charytonowicz, Reconsumption and Recycling in the Ergonomic Design of Architecture. Universal Access. Lecture Notes in Computer Science (Human-Computer Interaction. Ambient Interaction), Vol. 4555, (2007) pp. 313-322.

[18] P.A., Jensen, Value concepts and value based collaboration in building projects. In: S. Emmitt and M. Prins (Eds.) Proceedings of the CIB W096 Architectural Management, CIB, Rotterdam, 2005, 3-10.

[19] M. Himanen, The intelligence of intelligent buildings. The feasibility of the intelligent building concept in office buildings. Thesis (PhD). VTT Building technology, Espoo, Finland, 2003.

[20] N. J. Klugengseth and G. K. Hansen, What is building's usability? Retrieved online May 5 2010 http://www.metamorfose.ntnu.no/Artikler/What\%20is $\% 20 \mathrm{a} \% 20$ buildings\%20usability EuroFM09.pdf

[21] A. P.E. Lewis, Designing For Energy-Efficient Operations and Maintenance, August 1, 2010 http://www.esmagazine.com/Articles/Feature Article/B NP_GUID_9-5-2006_A_10000000000000873588

[22] W.J Peacock, The Maintenance of Building \& Structure, Municipal Engineer 3 (1986)

[23] Z. B. Brown, Occupant comfort and engagement in green buildings: Examining the effects of knowledge, feedback and workplace culture, PhD. Thesis, The University of British Columbia Vancouver, Canada, 2009

[24] J. Nicol, J. and M. Humphreys, Adaptive thermal comfort and sustainable thermal standards for buildings. Energy and Buildings, 34 (2002), pp. 563- 572.

[25] T. Erlandson, K. Cena, R. De Dear and G. Havenith, Environmental and human factors influencing thermal comfort of office occupants in hot-humid and hot-arid climates. Ergonomics, 46:6 (2006), pp. 616-628

[26] E. Shove, H. Chappells, L. Lutzenhiser and B. Hackett, Comfort in a lower carbon society, Building Research \& Information 36:4, (2008) pp. 307-311. 